\title{
RADICAL TEACHER
} A SOCIALIST, FEMINIST, AND ANTI-RACIST JOURNAL ON THE THEORY AND PRACTICE OF TEACHING

\section{Introduction to Radical Teacher's $100^{\text {th }}$ Issue}

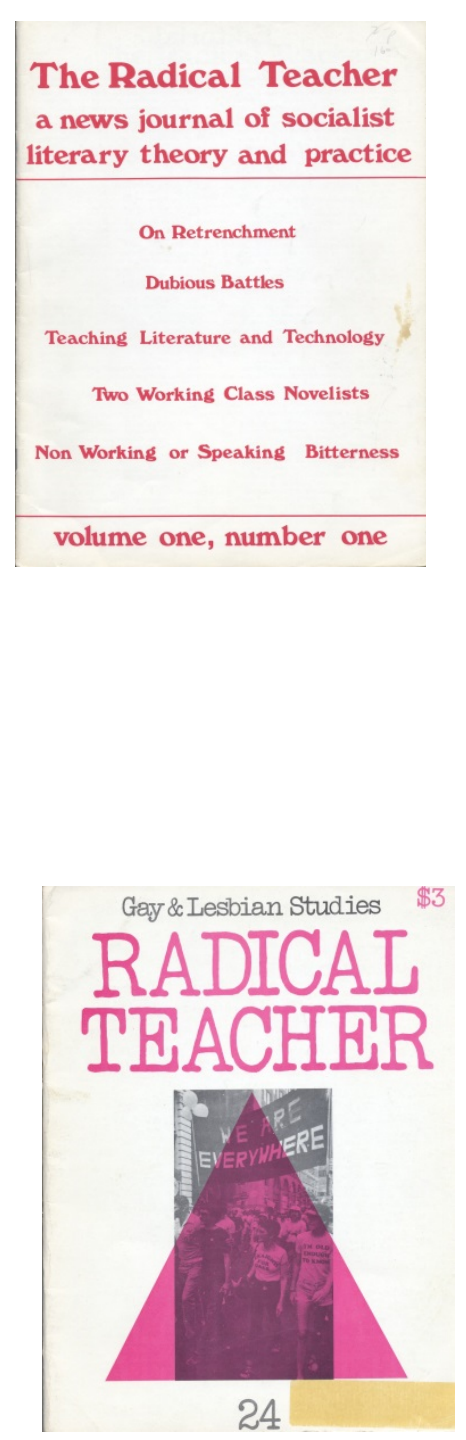

by Michael Bennett, Linda Dittmar, and Paul Lauter

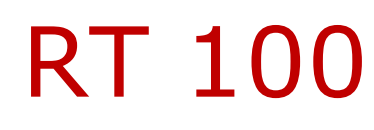

Anniversary Issue

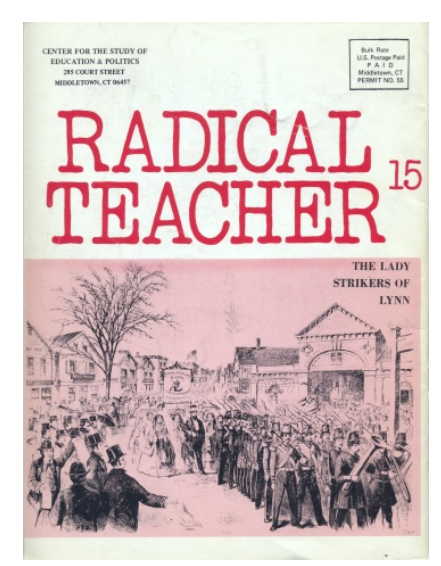

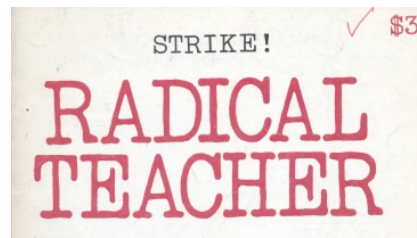

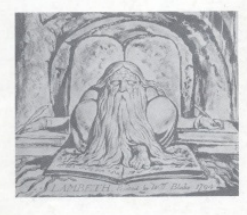

BACK TO BASICS

20

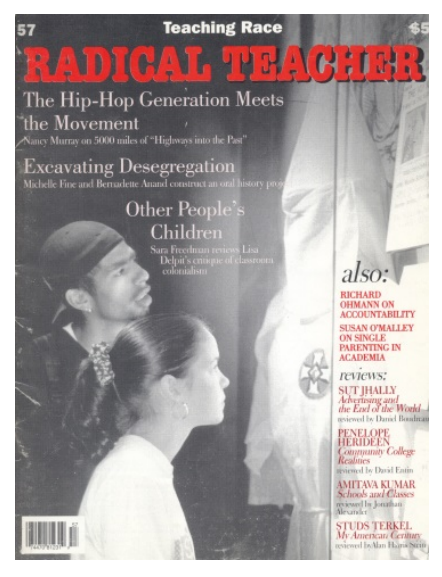


$\mathrm{T}$ o acknowledge and celebrate the $100^{\text {th }}$ issue of Radical Teacher, we are reprinting selected essays from our very first issue (December 1975) through our last year as a print journal (2012). Though the selection process was never entirely clear or agreed upon, we have tried to choose articles that reflect Radical Teacher's focus on class, race, and gender/sexuality, as well as on the socio-economic contexts of education and educational institutions, primarily but not exclusively in the United States. We also wanted some essays that emphasized theory and some that emphasized practice, always hoping that these foci came together as praxis. We tried to balance historical sweep with essays that stood out for their timeless insights and clarity. The essays are arranged chronologically, with certain themes and interests recurring.

According to the cover of the first issue, we were The Radical Teacher: a news journal of socialist literary theory and practice. The literary focus was an outgrowth of the fact that we were sponsored by the Radical Caucus in English and the Modern Languages, an affiliate organization of the Modern Language Association. The table of contents featured five articles: one essay and one interview critiquing higher education in the United States, two essays on literary study, and one on socialist journalism. All were written by university English professors who were members of the "Editorial Group" (later to become the "Editorial Collective"); four of those individuals who were part of the initial Editorial Group (Louis Kampf, Paul Lauter, Susan O'Malley, and Dick Ohmann) are now-retired professors who are still on the masthead and active in the journal. Given this social formation, it's not surprising that we have tended to focus on literary and cultural teaching at the university level.

However, the editorial that began this first issue, reprinted below, points to the Editorial Board's desire "to be open to other disciplines, rather than accepting the usual self-imposed divisions of standard academic journals. Our hope is also to address students, both graduate and undergraduate; all teachers of whatever level, those in public schools, those instructing graduate students, those in various alternative institutions around the country." The Board/Collective acted on that desire over the years, printing articles by and about what teachers from various disciplines do and think from grade school to grad school and in various alternative educational environments (e.g., community schools, prisons, and the Occupy movement). We have also tried to consider the organization and institutional structures within which radical teachers function at all levels of education.

That first issue, and many subsequent to it, also had on its back cover a quotation from Mao Tse-tung's "On Practice": "If you want to know the taste of a pear, you must change the pear by eating it yourself. If you want to know the theory and methods of revolution, you must take part in revolution. All genuine knowledge originates in direct experience." The editorial board had a number of hilarious discussions about that quotation, including one about maybe naming the magazine "The Pear." But sanity prevailed. It was not that the quotation misstated our goals, or some of them; but the provenance suggested a kind of sectarianism we wished then, and now, to avoid.

In the second issue, the subtitle of The Radical Teacher was gone. Beginning with the third issue, the definite article disappeared. Our first book review, of Editorial Group member Dick Ohmann's English in America, appeared in issue 3 , along with a spirited exchange between the author and other board members concerning audience: the efficacy of reaching out to liberals as opposed to rallying fellow radicals. A feature called "News for Educational Workers" began with issue 4. Both this feature and book reviews have been part of the journal ever since. Issue 4 also introduced the idea of a minicluster (called a "panel" at the time, as it originated in a panel at the MLA), on working class culture, which began $R T^{\prime} \mathrm{s}$ practice of alternating between miscellanies, miniclusters on one or more themes, and issues devoted exclusively to one theme. The first issue devoted to a single cluster topic was issue 6 on "Women's Studies in the 70s: Moving Forward." Though earlier issues had included notes on teaching specific books, films, or lessons, the section called "Teaching Notes" was added with issue 11 in 1979. When a subtitle reappeared with issue 67 in 2003, the name and the format were as they remain: Radical Teacher: a socialist, feminist, anti-racist journal on the theory and practice of teaching. The topics represented by this subtitle, along with the more general socio-political contexts in which radical teaching occurs or is inhibited, structure the selections made below.

When Radical Teacher became an online open-access journal in 2012, we revisited the question of whether we wanted to have an explicitly "socialist" orientation. The overwhelming if not unanimous consensus was that we needed the word "socialist" to indicate that our brand of radicalism goes beyond left-liberalism to a form of anticapitalism that is not a version of sectarian Marxism. In fact, part of our screening process for the editorial collective has long included efforts to maintain a radical socialist politics without falling into sectarian division, which is not to say that some of us aren't Marxists or Marxian, and that, like all thinkers on the left, we have definitely been influenced by Marx. One of the first essays we published that takes up this inheritance directly was Margaret Fay and Barbara Stuckey's "Who was Marx? What is Socialism? An Experiment in Socialist Pedagogy" in issue 9 (1978). Radical Teacher has never been interested in parsing Marxist theory-there are many journals that do so, badly or well-but we have always been involved in thinking of the implications of Marxist philosophy for social and political work, especially in the worlds of education. This emphasis is in keeping with our roots in the Radical Caucus of the Modern Language Association, which unlike the more theoretically focused MLA-affiliated Marxist Literary Group, with membership centered in research universities, is composed mostly of pedagogically focused radicals at colleges and teaching universities. Thus, over the years, $R T$ has had less to say about Marxist theory than about working class literature and culture. For instance, a few years after Fay and Stuckey's essay, Dan Tannacito's "Poetry of the Colorado Miners: 1903-1906" 15 (March 1980) offered an original work with primary 
documents as an important contribution to the field of working-class studies. Early in the twenty-first century, Lawrence Hanley's "Working-Class Cultural Studies in the University" 68 (Spring 2003) surveyed and expanded upon that field.

\section{When Radical Teacher became an online open-access journal in 2012, we revisited the question of whether we wanted to have an explicitly "socialist" orientation. The overwhelming if not unanimous consensus was that we needed the word "socialist" to indicate that our brand of radicalism goes beyond left-liberalism to a form of anti- capitalism that is not a version of sectarian Marxism.}

Our focus on gender and sexuality was evident from the beginning in terms of both who we are (striving for gender balance and LGBT-inclusiveness on the board) and what we publish. Kate Ellis's representative essay "Women, Culture, and Revolution" appeared in the second issue of $R T$ and Florence Howe's "Feminism and the Study of Literature" in the following issue, but the essay we chose to include from our early years is Elaine Hedges' "Quilts and Women's Culture" from issue 4 (1977), where it was part of a cluster on working class culture. We have always tried to explore the ways in which gender, race, sexuality, and class intersect. It is not accidental that most of the early writing on race in $R T$ is by women and feminist in orientation. One of $R T^{\prime}$ s strengths is precisely its recurrent highlighting of the intersectionality of modes of oppression and identity formation. The confluence of class and gender is the topic of Paul Lauter's "Working-Class Women's Literature-An Introduction to Study" (15, March 1980). Clusters/Special Issues on Women's Studies appeared in 1977, 1978, 1980, and 1984. Issues of gender and sexuality have been part of our repertoire ever since. Doug Honig's "The Gaylord Case: A Gay Teacher's Right to Teach," protesting a Washington State Supreme Court ruling that "being gay is and of itself enough to make one unfit to teach public school," appeared in the fifth issue. Perhaps our most reprinted essay, Tommi Avicolli's "He Defies You Still: The Memoirs of a Sissy," was published in our first Gay and Lesbian Studies issue $(24,1983)$. The word "queer" was added to the next such issue (45, Winter 1994). The fact that the " $T$ " all-too-often gets left out of LGBT was the subject of issue 92 (Winter 2011), "Beyond the Special Guest: Teaching 'Trans' Now," which includes Kate Drabinski's essay "Identity Matters: Teaching Transgender in the Women's Studies Classroom." Throughout the life of our journal, we have tried to examine some of the ways in which the cultural politics of gender, race, and class (and how they intersected) were, are, and will continue to change and develop.

Race and anti-racism were topics addressed in the journal's first editorial and revisited every year since then.
Three of the more well-known, and often reprinted, articles that $R T$ published on the intersection between gender and race were Gloria T. Hull's "Rewriting Afro-American Literature: A Case for Black Women Writers" (6, December 1977), Barbara Smith's "Toward a Black Feminist Criticism" (7, March 1978), and Mary Helen Washington's "These Self-Invented Women: A Theoretical Framework for a Literary History of Black Women" (17, November 1980). We thought about republishing these foundational works of Black feminist literary criticism, but decided to go with the less-often republished dialogue between Smith and Latina lesbian feminist Cherrie Moraga that adds sexuality and class into the mix: "Lesbian Literature: A Third World Feminist Perspective" $(24,1983)$, a dialogue, rather than a traditional essay, between two thinkers and activists who were responsible for opening and expanding previously neglected areas of study. Issue 33 (January 1988) on "Combatting Campus Racism" includes important syllabi by Gay Wilentz, Hoby Spalding, and Ronald Takaki that explore ways of incorporating work by and about African Americans, Latinos/Latinas, and Asian Americans into curricula. Issue 59 (Fall 2000) on "African American Studies at $Y 2 K^{\prime \prime}$ features book reviews about significant new work in the field. Issue 70 (September 2004) on "Race in the Classroom" offered many possibilities, but we chose Bree Picower's "Teaching Outside One's Race: The Story of an Oakland Teacher," which provides an intriguing blow-by-blow account of a young white teacher's fitful but ultimately successful transition to working in a school at the center of the "Ebonics" controversy. It provides compelling portraits of teachers and a community in tandem with self-reflection on the writer's own development. Issues 80 (Winter 2007) on "Teaching Beyond Tolerance" and 97 on "Hip-Hop and Critical Pedagogy" made notable contributions to $R T^{\prime}$ 's publications on race and racism. $R T$ has also published significant essays on Asian American studies (such as Ruth Yu Hsiao's "A Practical Guide to Teaching Asian-American Literature" 41 (Spring 1992) and on postcolonial literature (82, Summer 2008).

\section{Race and anti-racism were topics addressed in the journal's first editorial and revisited every year since then.}

We mention this last category because we feel that postcolonial studies, at its best, tries to think about issues of identity (ethnic, racial, gendered, and economic) as they are appropriated and politicized in national, transnational, and international contexts. In this respect, our focus on postcolonial and transnational issues is part of $R T^{\prime} s$ inclusive analysis of how people-bodies-find themselves in interlocking modes of oppression. Various issues of $R T$ have tried to push against the U.S.'s insular self-definition to internationalize our sense of solidarity/solidarities. The clusters on "Peace Studies" (26, June 1984), "Globalism" (61, Fall 2001, and 62, Winter 2001-2002), "Teaching in a Time of War" (72, Spring 2005, and 74, Fall 2005), and "Immigration" (84, Spring 2009) helped to internationalize 
our focus (along with older and recent pieces about teaching in Nicaragua, Mexico, Kurdistan, and Congo).

As for essays that provide a socio-economic critique of the historical and ideological contexts of education in the United States and beyond, it seems woefully prescient that the editorial in our very first issue, along with an essay by Paul Lauter, address the issue of "retrenchment" as a managerial ploy to undermine and dissipate the political energy of radical educators. Louis Kampf's "Annals of Academic Life: An Exemplary Tale" 21 (1982) provides an insider's narrative of the conservative pressures on departmental politics that will seem all too familiar to most radical teachers. Early special issues on "The Politics of Literacy" (8, 1978), "The Academic Profession" (11, 1979), and "Standardization" $(31,1986)$ also seem sadly current because of the ongoing conservative and neoliberal assaults on the left's efforts to make education something other than a disciplinary mechanism. From the beginning, $R T$ has applied a radical analytic framework for understanding the changing dynamics of educational structures. We have consistently provided a voice questioning the ways in which ever-evolving managerial policies have attempted to reshape education to meet neoliberal goals. Surely one of the primary assaults on radical ideals of public schooling today is the charter school movement. Our chosen essay on this topic is David I. Rubin's "The Charter School Law in Massachusetts: Analysis, Commentary, Wish" (49, Fall 1996). One of the greatest institutional challenges facing radical teachers in postsecondary institutions is addressed in Michael Bennett and Jacqueline Brady's "A Radical Critique of the Learning Outcomes Assessment Movement" 94 (Fall 2012): 34-47. Many of the issues discussed in these two essays are placed in historical context by Richard Ohmann's "Historical Reflections on Accountability" (57, Fall 1999).

Other essays that we've chosen to republish don't seem to fit into the neat parameters of this introduction. Patty Lee Parmalee's "Teaching Nazi Culture" (8, May 1978) was a favorite of the Editorial Collective. Marilyn Frankenstein's engaging "A Different Third R: Radical Math" 20 (1982) discusses the way "arithmetic skills [can be] learned through political application." We wouldn't want to overlook the role that art and graphics have played in the history of $R T$ as another forceful mode of social analysis and criticism which we see as integral to our critical perspectives. In issue 81 (Spring 2008), Nick Thorkelson provided a visual homage to our first Art Director in "Tribute to the Work and Life of Elizabeth Powell (19302007)." We also owe thanks to Shana Agid who served as Art Director for a number of years after Liz's death, before we left it up to the editors of each issue to provide their own artwork. Various essays in $R T$ have also dealt with the teaching of art, film, and other media from a radical perspective, as indicated by Linda Dittmar and Joseph Entin's "Introduction" to Issue 89 (Winter 2010) on "Jamming the Works: Art, Politics, Activism," which is comprehensive, clear, and undogmatic in its consideration of the relation of artistic production to political activism. David B. Downing's "What Does Neoliberalism Have to Do with Teaching Research Writing?" 85 (Fall 2009) describes his teaching of "Research Writing," a required humanities service course at Indiana University of Pennsylvania, a school with a big split between publicly funded academic activities and privately funded fancy dormitories (for those who can afford them). Various readings, videos, discussions, and short writings lead up to and develop a framework for a longer research project (on topics of the students own choosing) called "Neoliberalism and Me." Though we've said that these essays don't seem to fit into the categories delineated earlier, we'd argue that they explore issues of class, gender, and race in pursuing the general mission of radical teachers to promote critical thinking. As educators, we share this emphasis with "the liberal professor." As radicals, we put critical thinking in the service of a radical critique of current social/economic/gender/race practices and oppressions. These pieces emphasize thinking-writing, figuring, reading, seeing movies and media, producing art and music as empowering modes of resistance.

\section{Putting together this selection of essays from our first 100 issues has allowed us to re-experience a lot of great writing about the politics of pedagogy and to think more deeply about what radical teaching entails.}

We encountered another challenge to the system we've used for selecting essays when confronted with issues that as a whole addressed important topics but within which we found it difficult if not impossible to choose one representative essay. In such cases, we have chosen not to reprint a specific article but we would like to call your attention to these issues as worthy of note. The first $R T$ issue on prisons and education (16) was called "Con Ed," and it appeared in 1980. Subsequent issues on this topic-"Teaching Against the Prison Industrial Complex" (88, Summer 2010) and "Teaching Inside Carceral Institutions" ( 95, Spring 2013)-indicate our ongoing commitment to dismantling the Prison Industrial Complex. Efforts to reach beyond our usual focus on the humanities include issues on "Health Care and Science Teaching" (19, 1981), "Women and Science" $(30,1986)$, and "Computers and Technology" ( 63, Spring 2002). Other issues from which we couldn't choose one specific article that stood out but we found the totality to be of note include 26 on "Peace Studies" (1984); 29 on "Sexuality" (1985); 40 (Fall 1991) on "Mississippi Freedom Schools;" 47 (Fall 1995) on "Disability Studies;" 61-62 (2000-2001) on "Globalization," which includes two fine essay on teaching about sweatshops (one by John Miller and the other by Robert J. S. Ross); and issues 72 \& 74 (2005) on "Teaching in a Time of War." One issue that was repeatedly mentioned by members of the Editorial Collective as providing a stunning mix of insightful articles, moving poetry, great artwork, and socio-historical import is our first online issue $(96,2013)$ on "Occupy and Education," edited by Joseph Entin, Dick Ohmann, and Susan O'Malley.

Not surprisingly, a lot of the early material in Radical Teacher is about what to teach (i.e., challenging the 
canon), not about how to teach (i.e., pedagogy), which is quite different from the focus on praxis that evolved over the years. The battles over the canon were essential early on, but now they have to a great extent been assimilated into the curricula nationally (and variously internationally). Some of the 1960 s ideas about pedagogy were mainstreamed too, though they are now being cut back and/or eliminated through the "assessment" movement and budgetary/corporate development. Teaching to tests, teaching online, shifting back to the lecture mode, and the huge reliance on underpaid temporary instructors and graders who have little incentive to form any commitment to their students are all eroding liberal education, let alone radical. Another limitation we have faced is that $R T$ contributors have tended to focus on educators and education in the United States - though we have made a consistent effort to address global issues from early essays on teaching in Nicaragua and third world film to more recent discussions of teaching in Israel/Palestine and Kurdistan. As Radical Teacher looks to our next 100 issues, we hope to further explore the unresolved conflicts between the politics of pedagogy, the content of what we think people need to understand, and the sources of power and control in schools and colleges.

Putting together this selection of essays from our first 100 issues has allowed us to re-experience a lot of great writing about the politics of pedagogy and to think $m$ deeply about what radical teaching entails. It concerms something more than the questioning that happens in all good classes: an inquiry that insists on thinking against the grain (an excellent early feminist concept)-on taking nothing for granted; on always asking whose interests are being served by this or that way of thinking; on what questions are not yet being asked and which ones should be asked and why; on what's missing, rather than just what we know about what's there. It's an insistent rummaging for the suppressed knowledge and especially helping us, teachers and learners, understand the responsibilities of thinking and inquiry. It is also an insistent inquiry into the ways institutions-schools, factories, prisons, corporations, the military, etc.constrain our thinking and attempt to suppress such questioning.

Another thing we appreciate from the overview of our work, and the cross section $R T 100$ provides of it, is the sense of interconnectedness of these issues. Though each of us works in her/his own limited place-one's classroom, one's union, one's activist group, one's prison, one's high school or university or community program $-R T$ reminds us of our interconnectedness! We can only put our efforts where we are, but our work needs to be informed by an awareness of and identification with other struggles that we hope Radical Teacher will be part of for a long time to come.

[In addition to showing our chronology in content, the Radical Teacher collective also wanted to show our changes in appearance and decided to add all of our original graphics and covers to our reprinted articles. To make this possible, Bob Rosen not only translated all the reprinted articles into Word but also scanned all the original graphics and covers, for which we owe him a great debt of gratitude.]-The Managing Editor

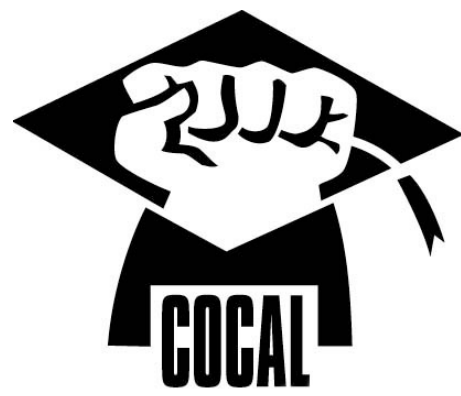

Contingent Academics Unite!

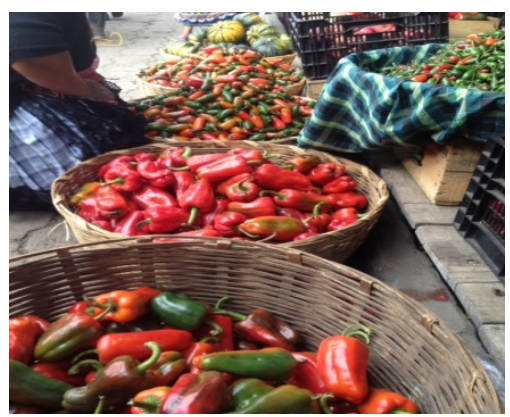

RT 98 TEACHING THE FOOD JUSTICE MOVEMENT

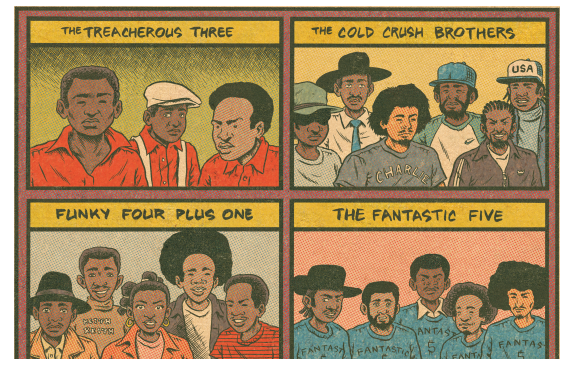

RT 97 HIP HOP AND CRITICAL PEDAGOGY

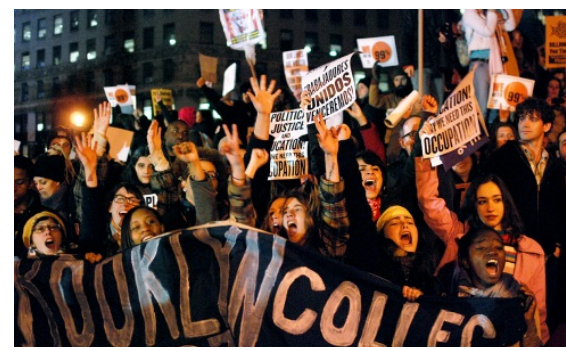

RT 96 OCCUPY AND EDUCATION

RADICAL TEACHER'S FIRST FOUR ONLINE OPEN ACCESS ISSUES

RT 96 TO RT 99 
